\title{
Food Contamination with Glyphosate and Other Herbicides
}

\author{
W Jean Dodds* \\ Hemopet, 938 Stanford Street, Santa Monica, USA \\ *Corresponding author: W Jean Dodds, Hemopet, 938 Stanford Street, Santa Monica, California, USA
}

\begin{tabular}{lll}
\hline ARTICLE INFO & & ABSTRACT \\
\cline { 1 - 1 } $\begin{array}{ll}\text { Received: } \\
\text { Published: January 30, } 2020\end{array}$ & & $\begin{array}{l}\text { Citation: W Jean Dodds. Food Contamination with Glyphosate and Other Herbicides. } \\
\text { Biomed J Sci \& Tech Res 25(3)-2020. BJSTR. MS.ID.004214. }\end{array}$ \\
\hline
\end{tabular}

\section{Mini Review}

Glyphosate (chemical name, N-phosphonomethylglycine) is the world's most widely used herbicide in homes and for agriculture [1-4]. It competitively inhibits the enzyme enolpyruvylshikimate phosphate synthase thereby blocking the production of chorismate, an intermediate for the biosynthesis of phenylalanine, tyrosine and tryptophan, and chelating manganese [1,2]. It is sprayed on genetically modified food crops such as corn, canola (rapeseed), and soy, and is used as a desiccant prior to harvest on crops such as peas, beans, lentils, oats, barley, and potatoes to increase crop yield $[1,2]$. Levels of glyphosate and its main degradation product, AMPA, continue to increase in foods and water supplies, and glyphosate run-off occurs into adjacent areas [1]. However, significant safety issues have surfaced about its use in Europe and the Americas; and a Class Action lawsuit concerning its use was successfully concluded or an individual that contracted non-Hodgkin's lymphoma [1, 5]. This chemical and AMPA also has been associated with causing nonalcoholic fatty liver disease and genomic DNA damage [6]. It has been found in childhood vaccines and is associate with endocrine and microbiome disruption at very low concentrations, especially when used with surfactants and emulsifiers [1]. The International Agency of Research on Cancer classified glyphosate as a Grade 2a carcinogen (probably carcinogenic to humans), a fact still contested by some regulatory agencies and scientists not only from the existing science, but also from allegations of political and industrial bias [2-5]. It is little wonder that the consumer public and even many scientists still cannot agree on this contentious, controversial topic.

More recent studies suggest subtle health risks of glyphosate. In 2018, researchers at Cornell University in the U.S. looked at the amount of glyphosate in 18 commercially available companion pet foods [7].

a) Glyphosate was detected in every product.

b) Glyphosate concentration was correlated with crude fiber content of plant products.

c) Average daily intake of glyphosate was estimated to result in exposures that were $0.68-2.5 \%$ of those for humans in the U.S. and E.U.

d) The most contaminated pet foods result in glyphosate exposures of $7.3 \%$ and $25 \%$ above the average daily intake for humans.

e) Pet exposure is $4-12$ times higher than that of humans on a per kilogram basis.

Transgenerational inheritance examines the environmental factors including toxicant exposures that can affect gene activation and suppression in first generation and future generations. In 2013, glyphosate was detected in the urine and different organs of Danish cows and hares, rabbits, and humans. However, cows kept in GMO-free areas had significantly lower glyphosate concentrations in their urine than cows conventionally housed. In 2014, these authors found glyphosate in tissues from malformed piglets [8]. In 2016, a high incidence of birth defects raised concerns about the teratogenic potential and resultant birth defects of GBHs after these chemicals were found in areas of intensive GM-soy planting $[3,4]$.

Investigators from Brazil reviewed 12 published studies testing potential associations between glyphosate and reproductive failures, birth defects, neonatal disorders, and childhood diseases 
[4]. They found that except for an excess of Attention Deficit Hyperactivity Disorder among children born to those applying glyphosate, there were no significant associations between use of this herbicide and adverse pregnancy outcomes. However, the authors concluded that "owing to methodological limitations of existing analytical observational studies, and particularly to a lack of a direct measurement (urine and/or blood levels), or an indirect estimation of exposure that has proven valid, these negative findings cannot be taken as definitive evidence that glyphosate, at current levels of occupational and environmental exposures, brings no risk for human development and reproduction" [4].

Since then, a 2018 study used pregnant female study and exposed them to low levels of glyphosate in early pregnancy; a control group was not exposed to glyphosate. Rats of both groups and sexes were studied at the subsequent 3 generations [3]. The third transgenerational generation test group had no direct exposure to glyphosate. All rats were sacrificed at 1 year of age. The tissues of the glyphosate exposed group had renal disease on histopathology, and some females had larger uteri with fluid filling the lumen. Testicular changes were insignificant in the direct exposure and transgenerational offspring but were increased in the second germline generation. Prostatic changes appeared 3 times more often in third generation glyphosate-exposed male rats than in controls. Further, F3 females had 4 times the control rate of kidney disease. Cystic ovarian disease was higher in the second and third glyphosate-exposed generations [3]. Tumor development (mammary adenomas) was increased significantly in second generation glyphosate females, but not in the first or second lineages; male rats also showed these tumors. Delayed puberty occurred in females in the second glyphosate generation and occurred in males in both first and second generations. Significant parturition abnormalities were noted in glyphosate mothers carrying third generation fetuses. Obesity rates increased in second and third generation male and female groups. When sperm were evaluated, glyphosate promoted germline epigenetic alterations in DNA methylation. Thus, significant disease was present in their later generations [3].

\section{Similar Safety Concerns Apply to other Widely Used Herbicides/Pesticides, Namely}

chlorpyrifos (chemical name, 0, 0-diethyl 0-3,5,6trichloropyridin-2-ylphosphorothioate), is an organophosphate product that acts on the nervous systems of insects by inhibiting acetylcholinesterase. It has many brand names. Cholorpyrifos was classified as a medium level probable carcinogen hazard in 2018 and has been banned in 2019 for use in Hawaii, California, New York, and in many other countries $[5,9]$. dicamba (chemical name, 3,6-dichloro-2-methoxybenzoic acid) is another widely used, broad-spectrum herbicide. Many brand names also appear for this herbicide. Its primary commercial applications are weed control for grain crops, legumes, and turf areas; to control pastures, and for use with on succulents, ranges, and roadsides [10]. It increases plant growth rate so that they outgrow their nutrient supplies and die [10]. Dicamba has come under serious scrutiny recently as 2 of the largest independent seed sellers have pushed the U.S. government to bar farmers from spraying this weed killer in the summertime. Regardless, additional safety questions remain, namely: What effect does multiple chemical exposures have when they occur simultaneously or concurrently? Are transgenerational and other factors worsened in a dose-dependent fashion or otherwise?

\section{References}

1. Davoren MJ, Schiestl RH (2018) Glyphosate-based herbicides and cancer risk: A post-IARC decision review of potential mechanisms, policy and avenues of research. Carcinogenesis 39(10): 1207-1215.

2. Woźniak E, Sicińska P, Michałowicz J, Woźniak K, Reszka E, et al. (2018) The mechanism of DNA damage induced by Roundup 360 PLUS, glyphosate and AMPA in human peripheral blood mononuclear cellsgenotoxic risk assessment. Food Chem Toxicol 120: 510-522.

3. Kubsad D, Nilsson EE, King SE, Sadler-Riggleman I, Beck D, et al. (2019) Assessment of glyphosate induced epigenetic transgenerational inheritance of pathologies and sperm epimutations: Generational toxicology. Sci Rep 9(1): 6372.

4. de Araujo JSA, Delgado IF, Paumgartten FJR (2016) Glyphosate and adverse pregnancy outcomes, a systematic review of observational studies. BMC Public Health 16: 472.

5. Dan Flynn for Food Safety News (2018) $9^{\text {th }}$ Circuit orders EPA to stop 'stalling' and ban ag use of popular pesticide.

6. Mills PJ, Caussy C, Loomba R (2019) Glyphosate excretion is associated with steatohepatitis and advanced liver fibrosis in patients with fatty liver disease. Clin Gastroenterol Hepatol pii: S1542-3565(19)30361-1.

7. Zhao J, Pacenka S, Wu J, Richards BK, Steenhuis T, et al. (2018) Detection of glyphosate residues in companion animal feeds. Environ Pollution 243: 1113-1118.

8. Krüger M, Schrödl W, Pedersen IB, Shehata AA (2014) Detection of glyphosate in malformed piglets. J Environ Anal Toxicol 4: 1-2.

9. News Desk for Food Safety News (2019) EU votes against renewing chlorpyrifos approval.

10. Dodds WJ (2018) Perspectives: More safety issues about the widespread use of pesticides herbicides. J Am Hol Vet Med Assoc 53: 32-37. 


\section{ISSN: 2574-1241}

DOI: 10.26717/BJSTR.2020.25.004214

W Jean Dodds. Biomed J Sci \& Tech Res

(C) (P) This work is licensed under Creative Submission Link: https://biomedres.us/submit-manuscript.php

$\begin{array}{ll}\text { BIOMEDICAL } & \text { Assets of Publishing with us } \\ \text { RESEARCHES } & \text { - Global archiving of articles } \\ & \text { - Immediate, unrestricted online access } \\ & \text { - Rigorous Peer Review Process } \\ \end{array}$

